\title{
From Use to Influence: Student evaluation of teaching and the professional development of academics in Higher Education
}

\author{
Rejoice Nsibande \\ University of the Witwatersrand \\ Corresponding Author: Rejoice.Nsibande@wits.ac.za
}

(Submitted: 29 July 2019; Accepted: 7 May 2020)

\begin{abstract}
The literature raises concerns that Student Evaluation of Teaching (SET) is not always used effectively to transform teaching practice in higher education. This paper reports on a study that was conducted across four faculties of a research-intensive university in South Africa to examine 17 academics' engagement in a self-driven SET process. Kirkhart's integrated theory of evaluation influence was used to analyse the collected data. Findings indicate that participation in self-driven SET influenced the academics to reflect deeply on their approaches, to prioritise context specific challenges and to interrogate elicited feedback to better understand students and their own engagement with teaching and learning. I argue that the use of SET in evaluating performance, limits and underplays the importance of personal and contextual factors that are crucial to support effective practices. The paper suggests that to complement the unavoidable institutional standardised processes whilst ensuring effective SET, robust self-driven processes should be promoted.
\end{abstract}

Keywords: Evaluation influence, Student evaluation of teaching, University teaching evaluation, Professional development

\section{Introduction}

The literature on Student Evaluation of Teaching (SET) reveals an increasing demand for academics to be more accountable for their teaching and course practices (Blackmore, 2009; Nygaard and Belluigi, 2011; Chalmers and Hunt, 2016). Consequently, SET as a mechanism for feedback on teaching and course experiences has become an essential aspect to improve teaching (McCormack, 2005). There is general consensus on the value of soliciting students' experience to support reflection on the worthwhileness of teaching and course experience.

SET has two main purposes: to establish teaching effectiveness (accountability), and to support academics' professional learning to enhance the quality of teaching (developmental) (Edstrom, 2008; Blackmore, 2009; Chalmers and Hunt, 2016; Steyn, et al., 2019). When stakeholders (academics) closer to the teaching contexts identify the issues that need addressing, 
the purpose of SET should be clear and questions asked by academics have to be aligned to the purpose for SET to increase the usability of the data (Saunders, 2012).

SET needs to be conceptualised in a manner that demonstrates an appreciation of how teaching and learning takes place in different contexts and the complexity of the higher education space (Blackmore, 2009; Edstrom, 2011). However, because of performance-driven practices, SET prioritises accountability (Blackmore, 2009; Ball, 2012). Consequently, the process becomes bureaucratic, fault finding (blame the teacher), and punitive rather than developmental. There may also be disregard for the reality of different teaching contexts (Nygaard and Belluigi, 2011). In addition, the process is beset with power dynamics. First, the focus on academics' performance encourages students to use SET as an opportunity to 'speak back to power', and, second, some institutions (including the one where this study was conducted) use the SET reports as measures of teaching effectiveness. The neoliberal agenda in higher education and its underlying modernist view assumes that teaching contexts are the same and academics are solely responsible for learning (Ball, 2012). Consequently, the approach to SET is informed by a belief that teaching and course experience can be captured and summarised using algorithms to measure teaching effectiveness. This influences how SET is conducted and used to support institutional processes for rewarding academics. The power dynamics inevitably impact academics' engagement in the process as they have little confidence in the value or validity of the information generated and fairness of the process (Smith, 2008; Contandriopoulos and Brousselle, 2012). Therefore, in its current form, there is little evidence of SET's contribution towards the professional development of the academics (Smith, 2008; Blackmore, 2009; Ryan, 2015).

The perceived 'ineffectuality' of SET can be linked to the instrumental and performancedriven approach of the contemporary practice. There is concern that students are often not in a position to evaluate teaching because they do not have expertise on pedagogical and subject knowledge. Therefore, student feedback cannot be taken as 'a evaluation' of teaching although their feedback is useful as a resource for reflections. Evaluation of teaching is considered as much broader than students' experience. It is more accurately a process predicated on three factors: self-reflection, peer review, and student feedback (Chalmers and Hunt, 2016). The tension around students' ability to evaluate teaching and course experience has made SET interesting as a research area, in particular, the perceptions of stakeholders - academics and students - and how these perceptions may impact how people engage with SET (Chalmers and Hunt, 2016). Attention has also been paid to the tools used and questions that are prioritised (Blackmore, 2009; Steyn, et al., 2019); usability of the data generated (Saunders, 2012) and the effectiveness of SET information in improving the quality of teaching (Ballantyne, et al., 2000; Kember, et al., 2010).

Saunders (2012) distinguishes between use and usability of SET. In his view, 'use' refers to the manner in which evaluation findings become a resource to influence future practice, and 'usability' is about the extent to which the findings can be used. 'Use' is, therefore, dependent on findings and usable findings require investment in the design of SET and stakeholder ownership of the process. In short, SET should not focus only on teaching performance but should 
support efforts to ensure the improvement of teaching (Saunders, et al., 2005). The SET process should emphasise 'sense-making' and 'perspective-taking' to facilitate learning for all students. Therefore, academics should ask questions that facilitate understanding of the context that influences the learning process. Ryan (2015) argues that the approach taken and the type of SET tools can encourage academics to think carefully about the questions they pose consequently influencing students to provide responses that are considered.

Writing in the context of South Africa, Steyn, et al. (2019) emphasise the importance of the nature of SET tools when trying to increase the usability of information generated in the process. Their research was an attempt to respond to the shortcomings of surveys, such as questions that restrict students from sharing their teaching and course experiences. The suggestion is that academics should develop questions that are open-ended and relevant to their teaching context to allow students to share aspects of the teaching experiences from their perspective. Bovill (2011), too, acknowledges the importance of SET tools and cautions against viewing SET as a vehicle only for changing teaching practices. In his view, SET should also enable students to reflect on their engagement in the learning process. Student self-reflection is a crucial factor in reconceptualising SET as a learning tool.

Amongst others, Ballantyne, et al. (2000) and Contandriopoulos and Brusselle (2012) argue that, in principle, SET should identify areas of improvement in teaching and also staff development needs to enhance staff development. However, to encourage interest in issues emerging in SET reports, the academic staff and the students, as key stakeholders, should work together to identify priority areas for staff development and the enhancement of teaching quality (Chen and Hoshower, 2003).

In this paper, I report on a study that was conducted to examine academics' engagement in a self-driven SET process in a research-intensive university in South Africa. As the head of a unit focused on the evaluation of teaching and courses, I set out to examine the factors that contributed to academics engagement, the nature of this engagement and how engaging with self-driven SET influenced their professional development. In doing so, special attention was paid to aspects such as the academics' ownership of the process, how they addressed contextual issues, the quality of the information generated and its usability. Further, there was attention to how SET was conceptualised as a learning space for all stakeholders. Reconceptualising SET, if needed, required an acknowledgement of these factors in a way that complemented the standardised institutional processes.

\section{The institutional context}

In the institution where the study was conducted, SET is centrally managed by a unit that is responsible for the evaluation of teaching and courses, located in the Centre for Learning, Teaching and Development (CLTD). Institutional policy stipulates that such evaluations should include SET, peer reviews and self-reflection. However, in practice emphasis is more on SET. Individual academics initiate the SET processes - the processes are not imposed. In general, academics on probation tend to engage more in SET than academics that have been in the 
system for years. In addition, academics get involved in SET when preparing for promotion as SET reports are a requirement when applying for promotion or for probation confirmation.

In SET surveys, there are 10 standard questions and other questions are generated by the academics themselves or selected from a question bank. Academics are also allowed to select or design their own open-ended questions. Many academics select from the provided questions. Often the questions focus on what academics do when teaching and whether and how students are satisfied with the process. For example, in the institution the following are the core questions (mandatory) on teaching.

1. Are lectures presented in a logical way and easy to follow?

2. Does the lecturer use examples that support my understanding of the concepts covered in the lectures?

3. Do the facilitation methods of the lecturer challenge me to understand the concepts taught rather than to memorise content?

4. Does the lecturer provide opportunities for collaboration and interaction among students either in lectures or online?

5. Does the lecturer listen and respond appropriately when the class requests help during lectures?

6. Does the lecturer makes herself/himself available to students for consultation in accordance with agreed-upon consultation platforms (face to face or online)?

7. Do I feel my participation in class is valued and treated with respect?

8. Does the lecturer make assessment guidelines clear and easily available?

9. Does the lecturer provide constructive feedback for my assessment tasks to help me improve my work?

10. Have the lecturer's facilitation methods developed my ability to work independently?

Once completed, students' responses are processed, and a report reflecting an average score (ranging between 1 and 10; 1 being an extremely low score and 10 being an excellent score) is produced. The score reflects a view on the effectiveness of the teaching, as experienced by the students. Individual scores are compared with the university average, and a score lower than this average often indicates a problem needing intervention - thus indicating a use of SET as a 'fire alarm' (Edstrom, 2008). However, there is still no formalised or official system within the institution that describes the follow up actions to be taken once the reports have been released. Where teaching is unsatisfactory, the responsibility for improving resides with the academic concerned.

\section{SET and academic success}

Three aspects are critical in exploring how SET practices can be reframed to achieve greater student academic success; namely, a democratic and participatory practice (Ryan, 2015; Rebolloso, et al., 2005), an integrated theory of influence as an approach to understanding the 
broader benefits of SET (Kirkhart, 2000) and the principle of 'slowness' that ensures the necessary conditions for engagement (Trakakis, 2018). The three aspects are not mutually exclusive but, rather, inter-related. Without the involvement of students and academics in SET, it would be difficult to identify what needs to be in place to ensure student success. Implied in this partnership is an integrated theory of influence that should serve as a resource to both probe and identify broader benefits of SET for students and academics. As argued by Trakakis (2018) such influence is not possible unless there is a gradual process that promotes meaningful engagement.

It is therefore, crucial to think of the implications of the suggested partnership, especially how it can be made beneficial to all. In the partnership it is important to ensure that processes create opportunities for stakeholders to engage from their own perspectives rather than be influenced by dominant views. Drawing on Wang (2006: 9) when 'learning with others, participants coming from the more centered positions may need to be vigilant of unconscious superiority $\cdots$, participants coming from the more displaced positions may need to be mindful of an internalized inferiority (along with holding on to traditions as a defense)'. In the case of this study, drawing on Wang, academics and students are not participating in SET from the same position and this can influence the nature of the partnership. Positionality is a crucial element that shapes the nature of engagement in learning spaces aimed at transforming self for both academics and students during SET process. It is therefore important to think carefully about how the space is constructed to ensure that no group imposes its ideas or thinking - all can engage from their own perspectives.

Evaluation as a field underscores the importance of democratic and socially just approaches (Ryan, 2015; Rebolloso, et al., 2005). The participation of all stakeholders involved in the practice that is being evaluated is crucial. They should have a 'voice' not just by participating but also making decisions that direct the evaluation process. 'Voice' means stakeholders being able to identify areas to explore and determining the process that best suits particular contexts (Brewington and Hall, 2018).

Evaluation influence is experienced when people are engaged in the process itself rather than just working with the evaluation reports. In other words, giving space for stakeholders' voices requires time for in-depth engagement in the process. Walker (2017), Leibowitz and Bozalek (2018), and Trakakis (2018) emphasise the need for higher education to adopt 'slowness' in the way people engage in activities - SET in this case. In their view, a 'slow' frame of mind can promote the quality of engagement and reflexivity. Therefore, for evaluation to exert influence, mindfulness is needed to encourage reflection without being afraid to leave questions open, and avoid rushing to conclusions on issues that need further examination. Full immersion in the process opens up new insights that can influence understanding and practice. The approach emphasises creating opportunities for all stakeholders to empower themselves by developing critical awareness of their own contexts. However, to date this aspect has not been given sufficient attention in higher education (Smith, 2008; Blackmore, 2009).

The 'use' of information in evaluation reports to influence changes in practice is important (Smith, 2008; Saunders, 2012). However, over the years, the evaluation field has had to contend 
with the limiting nature of the notion of 'use.' The focus on use is often narrow and neglects other dimensions crucial to understanding evaluation influence. Kirkhart (2000:6) maintains that 'influence can be examined from multiple vantage points'. For a better understanding of evaluations, see Kirkhart (2000), Mark and Henry (2004), and Johnson, et al., (2014) who suggest an exploration of how they (evaluations) influence participating individuals and the systems in which they are located. Kirkhart (2000: 7) asserts that focus on influence provides an opportunity to 'examine [evaluation] effects that are multidirectional, incremental, unintentional, and noninstrumental'.

Kirkhart argues further that evaluation influence can be examined in terms of three dimensions: source, intention, and time. The first refers to the source of influence that generates change processes, which can be cognitive, affective, or political in nature. Cognitive elements include developing an enhanced understanding and awareness of both the evaluation process and the areas being evaluated. Affective elements include ways of feeling about the evaluation as well as feelings of worth that fuel motivation and self-empowerment. Political elements include dynamics of power and privilege embedded in the evaluation process surrounding the person being evaluated. These elements involve individuals being in charge of the process of their evaluation. The second dimension is intention, which is the extent to which influence is purposefully directed through evaluation. This can occur during the process or through the findings of the evaluation. Intention is predicated on the clarity of the purpose of the evaluation and the decisions made around it. It is important to note that evaluations can also exert influence in unintended ways. Kirkhart (2000) states that such influence should be explored in the reflection process. The last dimension is time, indicating that development is incremental and takes place over time. Evaluation influence occurs at different points in the evaluation process, that is, immediately, at the end of the cycle, and beyond the cycle. The implication here is that an evaluation process is open-ended - a continuous reflection process.

\section{Study design, process, and methods}

The aim of the study was to engage academics who had shown interest in experiencing an alternative way of conducting SET. These academics were identified from the annual records of requests kept by the CLTD. Since the project was also designed to facilitate professional development non-didactically, the academics were given the opportunity to develop awareness and the skills needed for meaningful engagement in the SET process. As the Head of Evaluations and also a staff development practitioner, my aim was to make the process transformative through supporting the participants' self-empowerment and change in SET practices (see Kirkhart, 2000). This transformative element prioritises alternative ways of seeing and appreciating the value of SET, and engagement of all stakeholders to support better understanding teaching contexts (Brewington and Hall, 2018). 


\section{Project Participants}

The selection of the participants was purposive and convenient (McMillan and Schumacher, 2006). Invitations with information on the research project (such as, the purpose and structure of activities together with the time commitment required) were emailed to selected academics who had volunteered to participate in a CLTD project. Participants were responsible either for a full year university course or part of a course. The aim was to give them an opportunity to explore areas of interest not covered in the institutional SET. They taught in four different faculties and had varying teaching experience. The numbers shown below are only of those who completed the project. Some academics who initially volunteered withdrew because of other pressing commitments to attend to. Table 1 provides these details.

Table 1: Numbers of participants from different faculties and their years of teaching experience

\begin{tabular}{|l|c|c|c|c|}
\hline $\begin{array}{l}\text { Teaching } \\
\text { experience } \\
\text { (years) }\end{array}$ & Engineering & Humanities & Science & $\begin{array}{l}\text { Commerce, Law } \\
\text { \& Management }\end{array}$ \\
\hline $\mathbf{0 - 3}$ & & 3 & 2 & 2 \\
\hline $\mathbf{4 - 7}$ & 3 & & & 1 \\
\hline $\mathbf{8}$ and longer & & 4 & 2 & \\
\hline
\end{tabular}

The project had five steps and different methods were used to engage the participants at the different points. The steps are summarised in Table 2.

The paper uses data generated in Step 3 (SET tools designed and implemented by the participants) and Step 4 (individual reflective notes on experiences) to explore the nature of evaluation influence. The task in Step 3 was meant to develop greater clarity on the purpose of the SET process by encouraging the academics to reflect on what they were doing. Before designing tasks, they thought about their teaching contexts in the different faculties and identified one area, not covered in the institutional process, to focus on. Thereafter, they designed tools considered appropriate for the evaluation, implemented the tools and reflected on their experience of the process. To promote engagement, the structure of the project allowed opportunities for group discussions. 
Table 2: The five steps of the research process

\begin{tabular}{|l|l|l|l|}
\hline Steps & Method & Details & Purpose \\
\hline $\mathbf{1}$ & Questionnaire & $\begin{array}{l}\text { Participants completed questionnaire on current } \\
\text { experience and practice of SET. } \\
\text { Gathered information on experience of SET, more } \\
\text { specifically opportunities and challenges. }\end{array}$ & $\begin{array}{l}\text { Exploring } \\
\text { individual } \\
\text { knowledge of SET. }\end{array}$ \\
\hline $\mathbf{2}$ & $\begin{array}{l}\text { Group } \\
\text { reflection }\end{array}$ & $\begin{array}{l}\text { Themes emerging from the questionnaire data used as } \\
\text { discussion points to develop a new consciousness of SET } \\
\text { (two groups engaged separately). }\end{array}$ & $\begin{array}{l}\text { Developing } \\
\text { evaluation literacy } \\
\text { - co-constructing }\end{array}$ \\
\hline $\mathbf{3}$ & $\begin{array}{l}\text { Designing } \\
\text { and } \\
\text { implementing } \\
\text { SET }\end{array}$ & $\begin{array}{l}\text { First, individual reflection on SET practice followed by } \\
\text { identification of the area to focus on and clarifying the } \\
\text { purpose of the evaluation. } \\
\text { Second, participants designed and implemented tools to } \\
\text { evaluate teaching activities and student engagement as } \\
\text { identified. }\end{array}$ & $\begin{array}{l}\text { Participants' in- } \\
\text { depth } \\
\text { engagement and } \\
\text { making decisions. }\end{array}$ \\
\hline $\mathbf{4}$ & $\begin{array}{l}\text { Individual } \\
\text { reflection }\end{array}$ & $\begin{array}{l}\text { Reflection on experience individually to provide insights } \\
\text { into explanations of SET practice and experience of } \\
\text { participants in the process. }\end{array}$ & $\begin{array}{l}\text { Making sense of } \\
\text { process and } \\
\text { related }\end{array}$ \\
\hline $\mathbf{5}$ & $\begin{array}{l}\text { Group } \\
\text { reflection }\end{array}$ & $\begin{array}{l}\text { Final reflection to allow sharing of experiences, benefits, } \\
\text { and concerns. Researcher shared initial thoughts on data } \\
\text { with participants. }\end{array}$ & $\begin{array}{l}\text { Evaluation literacy } \\
\text { through co- } \\
\text { construction of }\end{array}$ \\
\hline
\end{tabular}

\section{Management of data}

In managing the data the following aspects were given special attention: (a) the nature of the designed tools, their purpose and the focus of the questions; and (b) how the academics accounted for the tools selected and made sense of the collected data. This was done to identify how academics used the opportunity to engage with what was important to them and explain the tools selected and their experiences of the SET process. Table 3 indicates how the data was managed using Kirkhart's (2000) dimensions of evaluation influence. 
Table 3: Examples of how the data were coded using Kirkhart's (2000) dimensions of evaluation influence

\begin{tabular}{|c|c|c|}
\hline Dimensions & Nature of influence & Examples identified in the data \\
\hline \multirow{3}{*}{ Source } & Cognitive & $\begin{array}{l}\text { Understanding of evaluations demonstrable in self-designed } \\
\text { evaluations process. } \\
\text { Insights gained into the different areas evaluated. }\end{array}$ \\
\hline & Affect & $\begin{array}{l}\text { Comments on the worth of the evaluation process and/or the } \\
\text { usefulness of the generated insights. }\end{array}$ \\
\hline & Political & $\begin{array}{l}\text { How the evaluation enabled the participants to do what they } \\
\text { thought would be useful to them - use of 'voice'. }\end{array}$ \\
\hline Intention & Aim of the evaluation & $\begin{array}{l}\text { Agenda of the evaluation and what it enabled the participants } \\
\text { to do. } \\
\text { Clarity on the purpose of the evaluation and its alignment with } \\
\text { the designed tools. }\end{array}$ \\
\hline Time & $\begin{array}{l}\text { Immediate } \\
\text { Long term }\end{array}$ & $\begin{array}{l}\text { Affirmation of ways of thinking. } \\
\text { Change of practice to enhance student experience. } \\
\text { Intentions and thoughts on how insights will be used in the } \\
\text { future. }\end{array}$ \\
\hline
\end{tabular}

\section{Results}

In line with Bovill's (2011) ideas, the findings indicate that SET provided a learning opportunity for students and their lecturers. In general, the lecturers' understanding of the selected areas was enhanced as they processed feedback from students. They felt and viewed themselves and the overall process in a new way. Having had a chance to explore what mattered to them and understand why it mattered and how the insights gained could inform their future, SET practices seemed empowering for these academics. The findings are discussed in detail and analysed below drawing on data collected from four academics responsible for first-year courses with large numbers. Pseudonyms are used instead of participants' real names and course codes have been to ensure anonymity (Wiles, et al., 2008).

The data revealed the different but related dimensions of evaluation influence (Kirkhart, 2000). Therefore, it was important to look at each dimension separately as identified in the project.

\section{Cognitive influence: Developing an evaluative stance and voice}

Data on this aspect illustrates how the academics experienced cognitive development through designing evaluations that focused on issues they had selected in their respective teaching contexts (Saunders, et al., 2005; Saunders, 2012). In each case, the focus shifted from academics' teaching performance to issues that facilitated an understanding of the different teaching contexts and how students were participating in these contexts. Examples are provided below. 


\section{Case 1 - DWU}

The SET tool below was designed by participant DWU. It focused on how students were taking responsibility for their learning. The focus and nature of the questions they responded to thus facilitated the generation of 'usable' data both in terms of quality and relevance to the teaching context (Saunders, 2012).

\section{As a [course name] student, what is your level of participation in the following?}

Next to each statement tick either $\mathbf{H}$ or $\mathbf{M}$ or $\mathbf{L}$, referring to High, Medium, or Low participation in activities.

\begin{tabular}{|l|l|l|l|}
\hline Attending lectures & $\mathrm{H}$ & $\mathrm{M}$ & $\mathrm{L}$ \\
\hline Attending tutorials & & & \\
\hline Reading in preparation for lectures & & & \\
\hline Asking questions or making comments in lectures & & & \\
\hline Reading in preparation for essays & & & \\
\hline Participating in tutorial discussions & & & \\
\hline Asking questions or making comments in lectures & & & \\
\hline Discussing lecture, tutorial, or essay topics with classmates outside class hours & & \\
\hline Visiting libraries & & & \\
\hline Downloading academic journal articles from the internet & & \\
\hline Making use of course readings & & & \\
\hline Making use of internet sources & & & \\
\hline Reading articles and chapters carefully and all the way through & & & \\
\hline Reading further out of interest, beyond what the course requires & & \\
\hline Making extensive written or typed notes based on lectures, tutorials, or readings & & & \\
\hline Recording lectures or tutorials & & & \\
\hline
\end{tabular}

General comments: If at all, how effectively did you participate in the course, and what could increase your participation?

As a [course name] student, which of these course learning outcomes have you achieved in your view, and to what extent?

Next to each statement tick $\mathbf{H}$ or $\mathbf{M}$ or L, referring to High, Medium, or Low achievement of these outcomes.

\begin{tabular}{|l|l|l|l|}
\hline Gaining an understanding of the main questions and issues dealt with in the course. & $\mathrm{H}$ & $\mathrm{M}$ & $\mathrm{L}$ \\
\hline Acquiring knowledge of the main theorists and theories referred to in the course. & & & \\
\hline $\begin{array}{l}\text { Acquiring knowledge about the main lines of controversy or debate in the literature } \\
\text { referred to in the course. }\end{array}$ & & & \\
\hline Gaining an understanding of the strengths and weaknesses of the existing literature. & & & \\
\hline $\begin{array}{l}\text { Acquiring tools of analysis that can be employed to better understand the world } \\
\text { around you. }\end{array}$ & & & \\
\hline Improving writing skills. & & & \\
\hline Improving argument presentation skills. & & & \\
\hline Acquiring greater confidence about expressing views. & & \\
\hline
\end{tabular}

General comments: If anything, what could enable you to better realise these course outcomes? 
The responses to the statements could be used to indicate whether or not teaching was effective in supporting student learning. Besides giving feedback on their experiences and engagement, the students were also given the opportunity to engage in self-reflection on their learning processes - not common in standardised surveys (Blackmore, 2009; Bovill, 2011). Foregrounding students and academics as collaborators in learning is an aspect not prioritised in the institution's performance-focused SET. Another example is given below.

\section{Case 2 - MWU}

As evident below, the SET tool designed by participant MWU focused on students' nonattendance of lectures.

1. Overall, did you find that the lectures made a valuable contribution to the teaching programme?

\begin{tabular}{|l|l|l|l|}
\hline Yes & No & Maybe & Don't Know \\
\hline
\end{tabular}

2. What did you expect from the [name of course] lectures?

3. Did you find that the lectures for [name of course] met your expectations as indicated in Q2?

4. Please elaborate on your answer regarding Q3.

5. How many lectures for [course name] did you attend?

a. Average number (scale of 1 to 100)

6. When you did attend lectures, why did you attend the lectures? Choose all the reasons that applied from the following list.

\begin{tabular}{|l|l|}
\hline It's required. & \\
\hline They're helpful. & \\
\hline They're interesting. & \\
\hline They cover material not in the readings. & \\
\hline I had nothing else to do. & \\
\hline I just did. & \\
\hline & \\
\hline
\end{tabular}

7. When you didn't attend lectures, why didn't you attend the lectures? Choose all the reasons that applied from the following list.

\begin{tabular}{|l|l|}
\hline The lecture times were bad. & \\
\hline I had other commitments. & \\
\hline I couldn't get to campus. & \\
\hline I forgot to attend/forgot the lecture times. & \\
\hline I was sick. & \\
\hline I didn't find the lectures useful or valuable. & \\
\hline I didn't understand the lecturer. & \\
\hline I just didn't. & \\
\hline
\end{tabular}

8. Thinking about your lecture attendance, are you happy with the number of lectures you attended?

\begin{tabular}{|l|l|}
\hline I am happy with my lecture attendance. & \\
\hline I am happy, but I could have attended more lectures. & \\
\hline I am happy, and I attended just as many as I needed or wanted to. & \\
\hline I am unhappy, and I could have attended more lectures than I did. & \\
\hline I am unhappy, but I couldn't have attended more lectures than I did. & \\
\hline I don't care. & \\
\hline
\end{tabular}

9. Please let your lecturers know if there is anything in their lectures they do especially well.

10. Please make any specific suggestions as to how your lecturers could improve their lectures. 
Lectures form a core part of the teaching programme, along with tutorials and students' own self-study. As a result, focusing on both lecturer performance and students' reflections on their participation in the learning process through the attendance of lectures, was meant to help identify what students valued in the teaching and learning process. In MWU's view, managing and meeting students' expectations started with establishing whether or not they saw attending classes as beneficial. For those who did not attend, it was crucial that they are aware that class attendance is fundamental for learning in order to reconsider their choice. Drawing on Bovill (2011) and Ryan (2015) it can be argued that SET was used by MWU as a learning space created by academic/student partnership in the teaching and learning process. LWU emphasised similar aspects using a specific teaching approach.

\section{Case 3 - LWU}

The SET tool designed by LWU focused on getting students to think about their learning and how it was supported through the selected teaching approach.

On a scale of 1-5 (1 poor - 5 excellent), how would you rate your knowledge on the areas below?

\begin{tabular}{|l|l|}
\hline The role of the audiologist. & \\
\hline The anatomy and physiology of the auditory system. & \\
\hline General symptoms of ear pathology. & \\
\hline $\begin{array}{l}\text { Specific pathologies of the outer, middle, and inner ear, including aetiology, audiological } \\
\text { manifestations, and management. }\end{array}$ & \\
\hline Outline of the basic audiological test battery. & \\
\hline Introduction to the audiogram. & \\
\hline
\end{tabular}

On a scale of 1-5 (1 poor - 5 excellent), how would you rate your ability to integrate the basic test battery and the audiogram in order to identify various pathologies of the auditory system?

\begin{tabular}{|l|l|}
\hline Outer ear pathologies. & \\
\hline Middle ear pathologies. & \\
\hline Inner ear pathologies. & \\
\hline Impacted cerumen. & \\
\hline
\end{tabular}

On a scale of 1-5 (1 poor - 5 excellent), how would you rate the following teaching activities?

\begin{tabular}{|l|l|}
\hline Visual aids: The extensive use of pictures and diagrams during lectures. & \\
\hline Self-directed learning: Providing case history and/or audiograms for students to practise identifying \\
various pathologies. & \\
\hline $\begin{array}{l}\text { Direct instruction: The provision of lecture slides to guide further reading of the literature - 100\% } \\
\text { lecture attendance recommended. }\end{array}$ & \\
\hline Problem-solving activities and discussions during lectures. & \\
\hline
\end{tabular}

LWU used SET to create an opportunity for students to think about their learning and how it was supported through the teaching approach used in the course (problem-based learning). 
The institutional SET does not cover this specific way of engaging with students to improve teaching. SET was used as a tool for reflecting on and refining teaching interventions (Saunders, et al., 2005).

Looking at the cases above, there is a sense that the different self-designed tools shifted from focusing on academics' performance but were still assimilative rather than transformative for students. Although the SET tools focused on student engagement, it can be argued, students' dominant ways of thinking about their role in the teaching and learning process were not disrupted. As Ryan (2015) would argue, the tools reinforced the notion of students as consumers, hence priority was given to students' expectations and academics' performance. Drawing on Wang (2006), in order for SET to facilitate learning for both academics and students, it was important that the tools create new possibilities in renegotiating understanding of participatory or engagement practices in the learning process. The next case by GWU is an example of this renegotiation, though in a limited way.

\section{Case 4-GWU}

This participant's concern was about students' engagement and approach to learning. How students perceived engagement with learning activities and reflected on their responsibility for their own learning, was important to GWU. Her tool focused on students' engagement and approach to their learning.

Please answer the following questions as honestly as possible - you will be completely anonymous. In order to support YOUR learning in the course -

1. What should you CONTINUE doing?

2. What should you START doing?

3. What should vou STOP doina?

While this tool is commonly used in formative SET processes (Bovill, 2011), the focus is usually on the performance of the academic; for instance, what should the lecturer continue, start, and stop doing? Although it is important to elicit information on academics' performance, if this is the only focus of the SET tool then the tool will be based on flawed conceptions of the teaching and learning process (Nygaard and Belluigi, 2011). In contrast, GWU encouraged students to be responsible for the way they engaged in the learning process and the questions encouraged students' perspectives on engagement in their learning as argued by Steyn, et al. (2019).

The insights that the participants gained when processing the data enabled them to think more deeply about their teaching practices and also to question aspects of the data. The intention was not to work with data that were confirmatory, but to open the data for critical engagement and in a way that would inform future practice. Informed by the principle of 'slowness' (Trakakis, 2018), the academics paused and thought about the teaching and learning spaces they had created and the students' experience of these spaces. In some way, it seems involvement in the project helped them develop a positive attitude towards the SET process. 
The four SET tools indicate possibilities for alternative ways of thinking when academics own the process. As in the work done by Saunders, et al. (2005), here the cognitive influence was not just in the design of the SET tools, but also in reflecting and making sense of the data. For example, participant DWU said:

The students who said harsh things generally came across as weaker in class participation and achievement of learning outcomes too. How causality works here I cannot say. Did I appeal more to strong students and less to weak ones? Or did the critical students achieve fewer outcomes because of weaknesses in my teaching? A few students offered constructive points, and one said he/she found the course extremely interesting.

\section{Discussion}

Questions on lecturer performance in each SET tool indicate the power of the institutional context and how it influenced and shaped what the academics did. As pointed out by Ashwin (2008), institutional structures and established ways of engaging have power and influence over how people engage in practice. In the case of the project, the positive attitude towards self-driven SET and appreciation of the opportunity to engage in SET that differed from institutional practice, allowed the lecturers to focus on issues they considered important in supporting student learning. This suggests that given a chance to participate in self-driven SET, academics can empower themselves, ask questions and engage with data to think about current and future teaching practice. Below, I discuss each of these aspects in detail.

\section{The positive attitude towards evaluation}

It appears that the self-driven SET process - from identifying own areas to evaluating and designing and implementing tools, to processing the data (though at elementary level) - has led to a positive attitude towards SET. As indicated by Kirkhart (2000) and Brewington and Hall (2018) stakeholder participation in evaluation process is crucial in generating positive attitude towards the process. Below are some quotations from the individual reflections that support the suggestion [responses quoted verbatim]:

MWU: Though response rates still remained low, I did, however, get important feedback from those who did respond. I put in a lot of effort into simplifying some of the very complex arguments ... as these were things I had deliberately worked on, I am happy that it was noticed.

DWU: I would say that evaluations like this are worth undertaking in the future, provided the data is analysed more systematically than I was able to do ... if these provisos are satisfied, evaluations like this could provide useful information about gaps in student participation and facilitate a more rational assignment of resources. For example, are we spending too much on course packs students don't read? What could make course packs 
more readable? And are students getting enough information about libraries and how to use them?

GWU: I find Assessment of Lecturer Performance [ALP] - institutional survey - unhelpful. If you get a good, bad, or average score, that is one thing, but you have absolutely no idea why your score is what it is. I prefer the qualitative evaluations like this one - the students clearly tell you what they like or dislike, what they are struggling with, etc., so you have something defined for you that you can work on ... I want to move past the set questions and optional questions. I just keep getting the same stuff over and over, but I've never been allowed to do this.

Overall, the academics saw the relevance and benefit of SET in supporting their goals. They were positive about the usability of the data generated, to understand issues in teaching contexts and also to pose further questions for deeper engagement (Saunders, 2012). However, as highlighted in DWU's statement, it cannot be assumed that making sense of student feedback is easy and straight forward. DWU's reflections also captured the impact of the current way of engaging with SET, especially how it positions academics and students in the process:

DWU: I was a bit shy about undertaking this evaluation because I thought students might think that I was trying to turn the spotlight from myself to them in order to avoid judgement of my own performance. After all, I have 'power' over them, and evaluations are normally their chance to 'speak back' to my power. In all fairness to myself, I did provide opportunities for students to comment on the course in open-ended questions. And the responses to the second part of the questionnaire, which relates to achievement of learning outcomes, undoubtedly reflects on my success as a teacher.

In Kirkhart's (2000) framework, ownership is the political element of sources of evaluation influence as it relates to a process that encourages self-empowerment. 'The political dimension addresses the use of evaluation process itself to create new dialogue, draw attention to social problems, or influence the dynamics of power and privilege embedded in or surrounding the evaluand' (Kirkhart 2000: 10). Over the years, owing to the performative nature of the approach to SET in the institution in which this study was conducted, an underlying positioning of students as 'clients' to be satisfied by academics (Ball, 2012) downplays the partnership between academics and students that should be driving reflections on teaching processes and spaces. The partnership approach is critical in reversing feelings of powerlessness on the part of academics.

\section{Processes and spaces that reverse feelings of powerlessness in SET}

The participants felt empowered by the SET self-driven process. SET provided an opportunity to drive the process and select focus areas that were not externally imposed (Chen and Hoshower, 2005; Blackmore, 2009; Steyn, et al., 2019). The academics thus considered the 
process and spaces created as 'eye-opening' in different respects. They felt that as a learning space, it did not judge them, as is evident in the following two comments.

MWU: When designing the questions, I got to identify questions that I really wanted the answers to. I also didn't mind sending the tool to students, as I felt that there was a clear purpose and one that they could appreciate. I often feel that lecturer evaluations are a pain to everyone involved, and neither lecturers nor students really take it [SET] seriously.

LMU: This indicator did not only cover how much the students felt they know in terms of content, it extended to teaching methods and learning styles that were mostly matching. In addition, evident in the test marks, there was an improved class average. However, the areas that were marked as poor by a few students, gave me an opportunity to address those as areas covered in the exams preparation session, by providing an additional session/opportunity for learning.

It was in the process of imagining possibilities that the academics had to be clear about their intentions with SET. The intentions informed the significance and influence of the evaluation process and the way in which findings were used (Kirkhart, 2000; Saunders, 2012). Clarity of evaluation intention explained up front, enabled the design of evaluations that were aligned to it (the intention).

\section{Intentions Directing Influence}

The participants described the purposes of the evaluations as follows:

DWU (Case 1): ... designed to test the level of student participation in various aspects of the course - attending lectures and tutorials, preparing for lectures and tutorials, reading, asking questions, visiting libraries, and using course pack and internet sources ... asked students to comment on their achievement or otherwise in respect of various course outcomes.

MWU (Case 2): An issue I identified in my lectures and talking to other lecturers, was the fact that many students do not attend lectures ... I designed an online form ... to ask about what they expect from lectures, what affects their lecture attendance, whether or not they are happy with their lecture attendance, and some questions specifically about whether my lectures met their expectations.

GWU (Case 3): I decided to evaluate students instead (they had already done an evaluation of both me and the course). I thought it would be interesting to 'get inside their heads' and see how they approached their studies. 
LWU (Case 4): The evaluation form was intended to provide the lecturer with information on how the students understood the content, whether teaching methods met their learning styles, and their readiness for the final assessment.

Saunders (2012) explains how the relationship between clear intentions and evaluations informs the processing of data. The relationship generates usable data (see also Smith, 2008). Intentions guide continuous reflection on the evaluation and the issue that was evaluated. Thinking about the SET practice and insights developed are channelled accordingly.

In the case of this study, the SET generated insights that the academics used either in immediate processes or for reflecting on future teaching practice. They were thinking about the implications of the themes that were emerging in the student feedback and engaged with the information as they reflected on the issues they wished to deal with. The positive engagement with issues emerging from student feedback demonstrates what happens when academics own the SET process and feel what is important to their teaching context is prioritised. Ownership of the process generates positive feelings about the evaluations and encourages engagement (Kirkhart, 2000) and supports empowerment (Brewington and Hall, 2018). This engagement is demonstrated in the way DWU reflected on the data.

During the SET process, an opportunity was created to begin thinking about what was emerging, as shown in the following quote from DWU:

The data about ways in which students participate in the course was unexpectedly illuminating. As a generalised impression, it seems lots of students do not do much visiting of libraries, using of course pack readings, or taking of notes. They participate quite a lot in tutorials but relatively little in lectures. Mostly this data is confirming what I have suspected.

Clearly, the participant was grappling with issues as they related to him and his relationship with his students, even though he had no ready solution at hand. In another case, it was clear to GWU what needed to be done in future practice to support students. Here GWU indicates the intention to use insights to influence understanding of what needs to happen:

Of all the classes I have taught over the years, this is the one that has taken the longest to find its feet during the first year. In 2018 I am going to spend much of my introductory lecture advising them on how to cope at university, what is expected of them, and how university differs from school - basically managing expectations. The sooner students get the hang of being independent and stop expecting someone else to do it for them, the sooner they flourish.

The enthusiasm and commitment to explore what was happening and to think further about the implications for future practice were evident. It seems that providing the space for 
academics' voices in SET generates positivity and ownership of what is generated, both in terms of knowledge and also the value of that knowledge going forward in practice.

\section{Conclusion and implications for SET practice}

SET is generally understood as a process designed to pass judgement on teaching effectiveness. Therefore, an interesting question to ask is 'whose interests are prioritised when the questions are formulated - those of the academics or the institution?' (Blackmore, 2009). In current practice, academics are under scrutiny and considered responsible for student learning and little attention is given to student engagement even though a crucial element in the learning process. The teaching context is also largely ignored (Nygaard and Belluigi, 2011). In contrast, the self-driven SET process discussed in this paper, created space for attentive and mindful engagement and an opportunity for sense-making and perspective-taking. It thus revealed that choosing and directing what was valuable to academics, motivated them and generated usable data. The space created for self-directed SET was critical in supporting professional engagement in SET rather than compliance. It promoted a willingness to explore what was happening and accountability to the self. With the shared ownership of the processes (Rebolloso, et al., 2005), the role of academic developers shifted to being facilitators (who created spaces) and advisors (who provided needed information) to support effective teaching and learning. These were shifts aimed at breaking patterns that are reproducing flawed and unjust practices.

The findings discussed are specific and limited and therefore not generalisable; however, they still indicate how academics and student engagement may enhance and strengthen SET practices. They do not suggest a replacement of the institutional standardised SET system. It has a specific function. To address the limitations of the study, further research is needed on the sustainability of the approach proposed here and how it can be strengthened, bearing in mind the complexity of the higher education context in general.

\section{Author Biography}

Rejoice Nsibande is Head of Evaluation at Wits University responsible for the conduct of evaluation of teaching and courses. Her higher education is in the Curriculum Studies field. Her current research work is on the 'architecture' of evaluation in higher education and reconceptualisation of the practice.

\section{References}

Ashwin, P. 2008. Accounting for structure and agency in 'close-up' research on teaching, learning and assessment in higher education. International Journal of Educational Research, 47: 151-158.

Ball, S. 2012. Performativity, commodification and commitment: An I-spy guide to the neoliberal university. British Journal of Educational Studies, 60(1): 17-28. 
Ballantyne, R., Borthwick, J. \& Packer, J. 2000. Beyond student evaluation of teaching: identifying and addressing academic staff development needs. Assessment and Evaluation in Higher Education, 25 (3): 221-236.

Blackmore, J. 2009. Academic pedagogies, quality logics and performative universities: evaluating teaching and what students want. Studies in Higher Education, 34 (8): 857-872.

Bovill, C. 2011. Sharing responsibility for learning through formative evaluation: moving to evaluation as learning. Practice and Evidence of Scholarship of Teaching and Learning in Higher Education, 6 (2): 95-109.

Brewington, Q. L. \& Hall, N. H. 2018. Givin' Stakeholders the Mic: Using Hip- Hop's Evaluative Voice as a Contemporary Evaluation Approach. American Journal of Evaluation, 39 (3): 336-349.

Chalmers, D. \& Hunt, L. 2016. Evaluation of Teaching. HERDSA Review of Higher Education, 3: 25-55.

Chen, Y. \& Hoshower, L. B. 2003. Student evaluation of teaching effectiveness: An assessment of student perception and motivation. Assessment and Evaluation in Higher Education, 28(1): 71-88.

Contandriopoulos, D. \& Brusselle, A. 2012. Evaluation models and evaluation use. Evaluation, 18(1): 61-77.

Edstrom, K. 2008. Doing course evaluation as if learning matters most. Higher Education Research \& Development, 27(2): 95-106.

Johnson, J., Guetterman, T. \& Thompson, R. J. 2014. An integrated model of influence: Use of assessment data in higher education. Research \& Practice in Assessment, 9: 18-30.

Kember, D., Leung, D. Y.P. \& Kwan, K. P. 2010. Does the use of student feedback questionnaires improve the overall quality of teaching? Assessment and Evaluation in Higher Education, 27(5): 411-425.

Kirkhart, K. 2000. Reconceptualising evaluation use: An integrated theory of influence. New Directions for Evaluation, 88(1): 5-24.

Leibowitz, B. \& Bozalek, V. 2018. Towards a slow scholarship of teaching and learning in the South. Teaching in Higher Education, 23(8): 981-994.

Mark, M. M. \& Henry, G. T. 2004. The mechanisms and outcomes of evaluation influence. Evaluation, 10(1): 35-57.

McCormack, C. 2005. Reconceptualising student evaluation of teaching: an ethical framework for changing times. Assessment and Evaluation in Higher Education, 30(5): 463-476.

McMillan, J. H. \& Schumacher, S. 2006. Research in education: Evidence-based inquiry (7th ed.). London: Pearson.

Nygaard, C. \& Belluigi, D. Z. 2011. A proposed methodology for contextualised evaluation in higher education. Assessment and Evaluation in Higher Education, 36(6): 657-671.

Rebolloso, E., Fernandez-Ramirez, B., \& Canton, P. 2005. The influence of evaluation on changing management systems in educational institutions. Evaluation, 11(4): 463-479. 
Ryan, M. 2015. Framing student evaluations of university learning and teaching: Discursive strategies and textual outcomes. Assessment and Evaluation in Higher Education, 40(8): 1142-1158.

Saunders, M. 2012. The use and usability of evaluation outputs: A social practice approach. Evaluation, 18(4): 421-436.

Saunders, M., Charlier, B., \& Bonamy, J. 2005. Using evaluation to create 'provisional stabilities': Bridging innovation in Higher Education change process. Evaluation, 11(1): 37-54.

Smith, C. 2008. Building effectiveness in teaching through targeted evaluation and response: Connecting evaluation to teaching improvement in higher education. Assessment and Evaluation in Higher Education, 33(5): 517-533.

Steyn, C., Davies, C. \& Sambo, A. 2019. Eliciting student feedback for course development: The application of a qualitative course evaluation tool among business research students. Assessment \& Evaluation in Higher Education, 44(1): 11-24.

Trakakis, N. N. 2018. Slow Philosophy. The Heythrop Journal, 59(2): 221-239.

Walker, M. B. 2017. Slow Philosophy: Reading against the Institution. London: Bloomsbury Academic.

Wang, H. 2006. Globalization and curriculum studies: Tensions, challenges, and possibilities. Journal of the American Association for the Advancement of Curriculum Studies, 2: 1-17.

Wiles, R., Crow, G., Heath, S. \& Charles, V. 2008. The Management of confidentiality and anonymity in social research. International Journal of Social Research methodology, 11(5): 417-428. 